\title{
Gender and Patient Satisfaction with Primary Care: Tuning in to Women in Quality Measurement
}

\author{
CAROL S. WEISMAN, Ph.D., ${ }^{1}$ DEBORAH E. RICH, Ph.D. ${ }^{2}$ JULIET ROGERS, M.P.H., ${ }^{2}$ \\ KAREN G. CRAWFORD, M.B.A., ${ }^{1}$ CARLA E. GRAYSON, Ph.D., ${ }^{3}$ \\ and JILLIAN T. HENDERSON, M.P.H. ${ }^{1}$
}

\begin{abstract}
This study analyzes the relationship between patient gender and satisfaction with primary care visits, using 1999 survey data on 1691 women and 760 men making primary care visits at multiple sites affiliated with a large academic health system designated as a National Center of Excellence in Women's Health (COE). The main findings are that in multivariate analyses controlling for patient and visit characteristics, different aspects of the content of primary care visits are important to women and men. Women's overall satisfaction with visits is more dependent than men's on informational content, continuity of care, and multidisciplinarity. Men's overall satisfaction is more dependent on the personal interest shown in them by providers. No differences in satisfaction are found between those seen in sites affiliated with the COE and other primary care sites within the health system that are not core sites of the COE. We conclude that quality improvement and research in women's primary care could benefit from gender analysis of patient satisfaction data and from more gender-sensitive patient satisfaction measures.
\end{abstract}

\section{INTRODUCTION}

$\mathbf{P}$ ATIENT SATISFAction SURVEys frequently are used to provide measures of the quality of care from the patient perspective. The use of patient satisfaction surveys in primary care settings is increasing because of the growth of managed care and the use of health plan report cards. Over $95 \%$ of health maintenance organizations (HMOs) and $55 \%$ of preferred provider organizations (PPOs) use patient surveys of some kind. ${ }^{1}$ The Consumer
Assessment of Health Plans Survey (CAHPS) has been incorporated into the Health Plan Employer Data and Information Set (HEDIS), which is used to assess the performance of managed care plans. $^{2}$ Patient satisfaction surveys also are used in research comparing quality in different types of healthcare organizations. ${ }^{3,4}$ Yet women have been largely invisible in patient satisfaction research. The standard outpatient satisfaction instruments have not been developed with gender issues in mind and have not been analyzed for gender dif-

\footnotetext{
${ }^{1}$ University of Michigan School of Public Health, Ann Arbor, Michigan.

${ }^{2}$ University of Michigan Health System, Ann Arbor, Michigan.

${ }^{3}$ Department of Psychology, University of Michigan, Ann Arbor, Michigan.

This work was supported by a grant from the University of Michigan Office of the Vice President for Research for an interdisciplinary project on Quality Assessment in Women's Health Care; by the University of Michigan Women's Health Program; and by the University of Michigan National Center of Excellence in Women's Health (DHHS Contract No. 282-97-0071).
} 
ferences. This study investigates the relationship between gender and satisfaction with primary care visits and identifies issues of particular concern to women.

In theory, gender might affect the mean level of patient satisfaction or the relative strength of predictors of satisfaction. Evidence for gender differences in mean satisfaction levels is mixed. Some authors report a preponderance of evidence that women are more satisfied than men with medical care received, ${ }^{5}$ and some report that women are more critical of medical care than men. ${ }^{6}$ On the assumption that gender is associated with reporting of satisfaction, some investigators treat gender as a "patient mix" variable and adjust for it in analyses of between-plan differences. ${ }^{3}$ Nevertheless, a meta-analysis of 110 studies of patient satisfaction, using standard instruments, concludes that there is no average difference in satisfaction with medical care between women and men. ${ }^{7}$

As for the predictors of satisfaction, the literature suggests that women and men experience basic healthcare differently and may evaluate it based on different factors or weightings of factors. The fragmentation of women's primary care, in which routine reproductive services and other components of primary care often are provided by separate providers in separate visits, ${ }^{8}$ may contribute to women's more frequent experiences of access problems, lack of coordination across visits, or redundancies or gaps in services. Access issues might be evaluated differently by women and men because women make more primary care visits than men or confront specific barriers (e.g., less discretionary time, lack of enabling resources, such as child care). A study of gender differences in the predictors of patients' overall satisfaction with their primary care physicians in one managed care plan found that the direction of effects for most independent variables was similar for women and men but that effect sizes differed by gender. Some structural aspects of health plans, such as the perceived ease of scheduling appointments or changing physicians, had stronger effects on women's overall satisfaction than on men's. ${ }^{9}$

The quality of communication with providers also may be a more important determinant of women's than of men's satisfaction with primary care. Research shows that women are more likely than men to actively seek information from providers and to express more emotional content in medical encounters. ${ }^{10,11}$ Communication problems have been implicated in women's switching doctors. In the 1998 Commonwealth Fund Survey of Women's Health, $18 \%$ of women, compared with only $9 \%$ of men, reported that they had changed doctors because of dissatisfaction within the past 5 years. (The remaining persons had either not changed doctors or changed for other reasons). Among those who had changed doctors because of dissatisfaction, $65 \%$ of women, compared with $55 \%$ of men, cited communication problems as the main reason (e.g., the doctor did not listen to me, did not explain enough to me). ${ }^{12}$

\section{MATERIALS AND METHODS}

\section{Setting}

This analysis uses spring 1999 results from the University of Michigan Health System Office Visit Satisfaction Survey, which is administered periodically in all clinical settings within the health system to all patients seen during a 1-week period. A U.S. Department of Health and Human Services (DHHS)-designated National Center of Excellence in Women's Health (COE) since 1997, the University of Michigan Health System has been interested in gaining a better understanding of gender issues in outpatient satisfaction and added "patient gender" as a variable on the Office Visit Satisfaction Survey for the first time in 1998.

The health system serves a wide geographical area, including urban and rural locations. Primary care patients are drawn largely from a fivecounty area in southeast Michigan. The market area is $83 \%$ white, $12 \%$ African American, and about $4 \%$ Hispanic and Asian. About $11 \%$ of persons in the market area are uninsured, and $25 \%$ are publicly insured through Medicare or Medicaid. The health system includes over 25 geographically dispersed sites, including primary care sites that are affiliated with the COE and some that are not.

\section{The survey instrument}

The multidimensional self-administered satisfaction survey includes 20 items covering five domains: calling the office, checking in at the visit, the visit itself, facilities and amenities, and overall summary ratings of the visit. The items were developed over a period of years using mixed- 
gender patient focus groups to define excellent medical care and to assess the appropriateness of the survey questions. The dimensions and items are similar to those included in other generic outpatient satisfaction surveys. ${ }^{3,13-15}$ Ratings on the survey items are obtained on a 5-point scale (poor, fair, good, very good, excellent), with an option for "not applicable." This type of 5-point rating scale without a neutral category is preferred in much of the patient satisfaction literature because it has been found to produce greater variability in responses than 6-point "very satisfied" to "very dissatisfied" scales. ${ }^{16}$

The survey also includes items on perceived health status (poor to excellent), as better health status frequently is found to predict higher satisfaction with care ${ }^{13}$; the main reason for the visit, which reflects visits for routine care as opposed to visits for follow-up of a problem or treatment of an illness or injury; whether or not the visit was the patient's first one to the clinical site, which might reflect expectations for the visit; gender of the primary care provider seen, because the literature suggests that many women prefer female physicians and may be more satisfied with care provided by women ${ }^{17,18}$; patient gender; date of birth; race/ethnicity; educational level; type of health insurance; and enrollment in a managed care plan (HMO or PPO). Created variables (not reported by the patient) indicate the clinical area in which the patient was served and whether or not the clinical site is affiliated with the COE.

Core COE sites are defined as those in which medical or nursing personnel participate in institutional women's health programs emphasizing training and practice in comprehensive, integrated primary care for women. (This designation is not dependent on the gender composition of the site's patient population.) The mission of the national COE program emphasizes comprehensive care, including reproductive and nonreproductive components of care, the multidisciplinary nature of women's healthcare, and the translation of women's health research into clinical practice. ${ }^{19} \mathrm{COE}$ sites are expected to improve the integration of services provided in women's primary care visits, the continuity of care across visits, and the quality of communication with patients. Because this survey was conducted after the COE program had been in effect for 18 months, quality improvements consistent with the COE mission should have been implemented in participating sites by the time of the survey. Our hypothesis is that receiving primary care in a core COE site will be associated with higher satisfaction with care received among women but will have no effect on men's satisfaction with care.

\section{Sample}

The survey was completed by patients on a voluntary basis at office visits during a 1-week period in April 1999. The average response rate across clinical sites typically exceeds $60 \%$, which is high for point-of-service satisfaction surveys. The overall response rate for the primary care sites included in this analysis was $62 \%$. No data on nonresponders are available, but the demographics of respondents are similar to the total patient population of the health system during 1999.

This analysis focuses on adult patients (ages 18 and over) seen in three clinical departments in which primary care services are provided: family practice, general internal medicine, and, for women, obstetrics-gynecology. Routine obstetrics-gynecology visits are included because of a substantial body of research demonstrating that obstetricians-gynecologists provide primary care services and that nearly $50 \%$ of women use an obstetrician-gynecologist either as their primary care provider or in conjunction with a primary care provider for regular preventive care. ${ }^{20-22}$ However, prenatal care visits $(46 \%$ of all obstetrics-gynecology visits) were excluded from these analyses because of their unique nature. Clinical area is controlled in analyses to identify any effects of obstetrics-gynecology visits compared with other clinical areas. The sample for this analysis, therefore, includes 1691 women and 760 men making primary care visits in 13 clinical sites within the health system.

\section{Analyses}

Factor analysis of the satisfaction items revealed the same factor structure for women and men. Principal component factor analysis using varimax rotation with Kaiser normalization identified three factors with high internal consistency reliability: accessing care (6 items, Cronbach's alpha $=0.85)$, visit content $(7$ items, Cronbach's alpha $=0.95$ ), and amenities (4 items, Cronbach's alpha $=0.86)$. Summed scores for these three factors were computed.

Analytical methods include bivariate and mul- 
Table 1. Patient and Visit Characteristics by Gender

\begin{tabular}{|c|c|c|}
\hline & $\begin{array}{c}\text { Women } \\
(\mathrm{n}=1691)\end{array}$ & $\begin{array}{c}\text { Men } \\
(\mathrm{n}=760)\end{array}$ \\
\hline Mean age, years (standard deviation)* & $56.2(15.9)$ & $52.2(16.5)$ \\
\hline \multicolumn{3}{|l|}{ Race/ethnicity (\%) } \\
\hline White, non-Hispanic & 83 & 85 \\
\hline African American & 8 & 6 \\
\hline Asian & 5 & 4 \\
\hline Hispanic & 1 & 1 \\
\hline Other & 3 & 4 \\
\hline \multicolumn{3}{|l|}{ Education* (\%) } \\
\hline Less than high school & 7 & 9 \\
\hline High school graduate & 24 & 23 \\
\hline Some college, trade, technical school & 27 & 21 \\
\hline College graduate & 42 & 47 \\
\hline \multicolumn{3}{|l|}{ Health insurance* $(\%)$} \\
\hline Private & 78 & 75 \\
\hline Medicare & 14 & 18 \\
\hline Medicaid & 7 & 5 \\
\hline None & 1 & 1 \\
\hline \multicolumn{3}{|l|}{ Type of health plan (if insured) (\%) } \\
\hline $\mathrm{HMO}$ or $\mathrm{PPO}^{\mathrm{a}}$ & 60 & 58 \\
\hline Other & 40 & 42 \\
\hline \multicolumn{3}{|l|}{ Health status (\%) } \\
\hline Poor or fair & 18 & 19 \\
\hline Good & 36 & 37 \\
\hline Very good & 32 & 30 \\
\hline Excellent & 13 & 14 \\
\hline First visit to this clinical site (\%) & 13 & 13 \\
\hline \multicolumn{3}{|l|}{ Reason for visit ${ }^{*}(\%)$} \\
\hline Routine checkup & 36 & 28 \\
\hline Follow-up visit & 34 & 34 \\
\hline Illness & 27 & 28 \\
\hline Injury & 3 & 9 \\
\hline \multicolumn{3}{|l|}{ Clinical area $(\%)$} \\
\hline Family practice* & 28 & 35 \\
\hline Internal medicine ${ }^{*}$ & 42 & 65 \\
\hline Obstetrics-gynecology & 30 & - \\
\hline Primary provider gender (female) ${ }^{*}(\%)$ & 57 & 22 \\
\hline 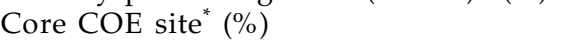 & 57 & 45 \\
\hline
\end{tabular}

${ }^{*}$ Gender difference is statistically significant $(p<0.05)$ by the Chi-square test or $t$ test.

${ }^{a} \mathrm{HMO}$, Health Maintenance Organization; PPO, Preferred Provider Organization; COE, National Center of Excellence in Women's Health.

tivariate approaches. Women and men are compared with respect to sociodemographic, visit, and satisfaction variables using Chi-square tests and $t$ tests as appropriate. Multiple logistic regression analysis is used to analyze predictors of overall visit satisfaction, separately for women and men. The dependent variable is a rating of "excellent," versus all other ratings, in response to the question: "Overall, how would you rate the care you received at the office/clinic?" The dependent variable is dichotomized due to its nonnormal distribution, in which $52 \%$ of respondents reported that their care was excellent. Hence, the adjusted relative odds reflect the increase or decrease in odds of reporting that overall care was excellent, adjusting for covariates.

Stepwise procedures are used in the logistic regressions. Patient characteristics (sociodemographic and health insurance variables) are entered in the first step, characteristics of the visit are entered in the second step, and the visit satisfaction factor scores are entered in the third step. This approach provides a conservative estimate of the effect of domain (factor) satisfaction on overall visit satisfaction by allowing patient and visit characteristics to first account for vari- 
Table 2. Mean Visit Satisfaction by Patient Gender ${ }^{a}$

\begin{tabular}{|c|c|c|c|}
\hline & Women & Men & $\begin{array}{c}\text { Gender } \\
\text { difference }^{\mathrm{b}}\end{array}$ \\
\hline \multicolumn{4}{|l|}{ Accessing care } \\
\hline \multicolumn{4}{|l|}{ Length of time between making appointment and day } \\
\hline of visit & 3.56 & 3.73 & $p=0.002$ \\
\hline Length of time on hold when making appointment & 3.49 & 3.58 & NS \\
\hline Courtesy of person on telephone who made appointment & 4.20 & 4.25 & NS \\
\hline Helpfulness of check-in staff & 4.25 & 4.27 & NS \\
\hline Promptness of check-in staff & 4.26 & 4.26 & NS \\
\hline Length of time at office/clinic before seeing doctor & 3.52 & 3.68 & $p=0.005$ \\
\hline Mean Accessing Care score & 3.91 & 3.98 & $p=0.018$ \\
\hline \multicolumn{4}{|l|}{ Visit content } \\
\hline Personal interest shown in you and your medical problems & 4.43 & 4.46 & NS \\
\hline $\begin{array}{l}\text { Doctor's ability to answer questions in a way you could } \\
\text { understand }\end{array}$ & 4.50 & 4.51 & NS \\
\hline Thoroughness of the examination treatment & 4.40 & 4.37 & NS \\
\hline \multicolumn{4}{|l|}{ How well the doctor knew what happened to you at other } \\
\hline visits at this office & 4.21 & 4.27 & NS \\
\hline Explanations of medical procedures and tests & 4.37 & 4.36 & NS \\
\hline Amount of time you spent with doctor during your visit & 4.23 & 4.22 & NS \\
\hline Overall satisfaction with nursing care & 4.30 & 4.34 & NS \\
\hline Mean Visit Content score & 4.35 & 4.36 & NS \\
\hline \multicolumn{4}{|l|}{ Amenities } \\
\hline Cleanliness of restrooms & 4.27 & 4.31 & NS \\
\hline Cleanliness of examination room & 4.40 & 4.43 & NS \\
\hline Clarity of directions to office & 4.33 & 4.33 & NS \\
\hline Ease of parking & 3.74 & 3.92 & $p=0.002$ \\
\hline Mean amenities score & 4.16 & 4.24 & $p=0.027$ \\
\hline \multicolumn{4}{|l|}{ Overall rating } \\
\hline $\begin{array}{l}\text { Overall, how would you rate the care you received at the } \\
\text { office/clinic? }\end{array}$ & 4.30 & 4.28 & NS \\
\hline
\end{tabular}

aSatisfaction items were answered on a 5-point scale (poor, fair, good, very good, excellent), with a higher score indicating greater satisfaction.

${ }^{\mathrm{b}}$ Gender differences in means were tested by the $t$ test.

ation in the outcome. Incremental contribution to variance explained by each step is computed.

\section{RESULTS}

To describe the study sample, Table 1 presents sociodemographic and visit characteristics by gender. Women are significantly older than men, with an average difference of 4.0 years, but other sociodemographic differences between women and men are not substantial. As expected based on the patterns of primary care use of women and men, women are more likely than men to be making a visit for a routine checkup, whereas men are more likely than women to be making a visit for treatment of an injury. Women are more likely than men to see female physicians and to make visits to core sites of the COE.
To test for mean gender differences, Table 2 compares women's and men's average ratings of their primary care visits. The items are grouped under headings corresponding to three factors described earlier, and factor scores are included. There are few statistically significant mean differences between women and men, but in each case of a significant difference, women are less satisfied than men. Women are less satisfied with the length of time between making an appointment and the day of visit, the length of waiting time at the visit before seeing the doctor, and the ease of parking. Women's mean scores on the accessing care and amenities factors are significantly lower than men's. However, there is no significant difference in overall rating of care received.

The relative strength of predictors of overall satisfaction with the visit were considered separately for women and men within a multiple re- 
Table 3. Stephise Logistic Regression of Overall Satisfaction for Women ${ }^{a}$ (Adjusted Relative Odds Ratios), $n=1165$

\begin{tabular}{|c|c|c|c|}
\hline & Step 1 & Step 2 & Step 3 \\
\hline \multicolumn{4}{|l|}{$\begin{array}{l}\text { Step 1: Sociodemographic and } \\
\text { insurance plan characteristics }\end{array}$} \\
\hline Age & $0.99^{* *}$ & $0.99^{* *}$ & 0.99 \\
\hline Perceived health status & $1.68^{* * *}$ & $1.65^{* * *}$ & $1.24^{*}$ \\
\hline Education (college graduate) & 0.99 & 1.03 & 0.99 \\
\hline \multicolumn{4}{|l|}{ Race/ethnicity } \\
\hline African American & 0.86 & 0.88 & 1.20 \\
\hline Hispanic & 0.75 & 0.78 & 0.88 \\
\hline Asian & $0.49^{* *}$ & $0.49^{*}$ & 0.57 \\
\hline Other & 1.13 & 1.16 & 0.70 \\
\hline White & (reference) & (reference) & (reference) \\
\hline \multicolumn{4}{|l|}{ Health insurance } \\
\hline Medicare & 1.08 & 1.08 & 1.03 \\
\hline Medicaid & $2.96^{* *}$ & $2.98^{* * *}$ & $7.50^{* * *}$ \\
\hline Uninsured & 2.02 & 2.03 & 3.25 \\
\hline Private & (reference) & (reference) & (reference) \\
\hline Managed care (yes) & 1.07 & 1.09 & 1.02 \\
\hline \multicolumn{4}{|l|}{ Step 2: Visit characteristics } \\
\hline \multicolumn{4}{|l|}{ Reason for visit } \\
\hline Follow-up & & 0.82 & 0.90 \\
\hline Illness & & 0.99 & 0.97 \\
\hline Injury & & 1.07 & 0.75 \\
\hline Routine & & (reference) & (reference) \\
\hline \multicolumn{4}{|l|}{ Department } \\
\hline Family practice & & 1.12 & 1.23 \\
\hline Obstetrics and gynecology & & 1.19 & 1.06 \\
\hline Internal medicine & & (reference) & (reference) \\
\hline Core COE site & & 0.88 & 1.11 \\
\hline Gender of physician (female) & & 1.12 & 1.07 \\
\hline \multicolumn{4}{|l|}{ Step 3: Satisfaction factors } \\
\hline Visit content & & & $12.25^{* * *}$ \\
\hline Access & & & $3.17^{* * *}$ \\
\hline Amenities & & & $1.77^{* * *}$ \\
\hline Pseudo $R^{2}$ & 0.049 & 0.052 & $0.454^{+}$ \\
\hline
\end{tabular}

aThe dependent variable is dichotomous: overall visit rated as "excellent" compared with other ratings.

${ }^{b} \mathrm{COE}$, National Center of Excellence in Women's Health.

${ }^{* * *} p<0.001 ;{ }^{* *} p<0.01 ;{ }^{*} p<0.05$.

${ }^{\dagger} \mathrm{By}$ the Chi-square test, the stepwise increment in the Pseudo $R^{2}$ is significant at $p<0.001$.

gression framework. (In combined models adjusting for all patient and visit variables, gender did not contribute significantly to variance explained in overall visit satisfaction.) Tables 3 and 4 , for women and men respectively, show the results of stepwise multiple logistic regression analyses. Among the patient characteristics, higher perceived health status is a significant predictor of overall satisfaction in the first two steps for men and across all steps for women. Asian women and men (compared with whites) report lower overall visit satisfaction in the first two steps, but the effect disappears in step three. Medicaid coverage (compared with private health insurance) predicts higher overall visit satisfaction for women in all three steps, but not for men.
Women Medicaid recipients may have lower expectations for care than other women and may find their expectations exceeded in these primary care settings.

Among the visit characteristics, the only variable attaining significance is the reason for the visit among men: visits for treatment of an illness (compared with routine visits) predict higher overall visit satisfaction. Among women, it is noteworthy that neither the reason for the visit, making an obstetrics-gynecology visit, making a visit to a core COE site, nor seeing a female physician attains significance as a predictor of overall visit satisfaction.

For both women and men, the three factor scores are significant positive predictors of over- 
Table 4. Stephise Logistic Regression of Overall Satisfaction for Men ${ }^{\mathrm{a}}$ (Adjusted Relative Odds Ratios), $n=540$

\begin{tabular}{|c|c|c|c|}
\hline & Step 1 & Step 2 & Step 3 \\
\hline \multicolumn{4}{|l|}{$\begin{array}{l}\text { Step 1: Sociodemographic and } \\
\text { insurance plan characteristics }\end{array}$} \\
\hline Age & $0.98^{* *}$ & $0.97^{* * *}$ & 0.99 \\
\hline Perceived health status & $1.69^{* * *}$ & $1.73^{* * *}$ & 1.30 \\
\hline Education (college graduate) & 0.97 & 1.00 & 0.86 \\
\hline \multicolumn{4}{|l|}{ Race/ethnicity } \\
\hline African American & 0.88 & 0.90 & 0.80 \\
\hline Hispanic & 0.50 & 0.53 & 0.55 \\
\hline Asian & $0.26^{*}$ & $0.24^{* *}$ & 0.23 \\
\hline Other & 1.15 & 1.17 & 0.55 \\
\hline White & (reference) & (reference) & (reference) \\
\hline \multicolumn{4}{|l|}{ Health insurance } \\
\hline Medicare & 0.56 & 0.55 & 0.65 \\
\hline Medicaid & 0.87 & 0.79 & 1.06 \\
\hline Uninsured & 1.02 & 0.90 & 1.51 \\
\hline Private & (reference) & (reference) & (reference) \\
\hline Managed care (yes) & 0.79 & 0.68 & 0.71 \\
\hline \multicolumn{4}{|l|}{ Step 2: Visit characteristics } \\
\hline \multicolumn{4}{|l|}{ Reason for visit } \\
\hline Follow-up & & 1.58 & $2.30^{* *}$ \\
\hline Illness & & $1.69^{*}$ & $2.48^{*}$ \\
\hline Injury & & 1.98 & 2.00 \\
\hline Routine & & (reference) & (reference) \\
\hline \multicolumn{4}{|l|}{ Department } \\
\hline Family practice & & 1.26 & 1.26 \\
\hline Internal medicine & & (reference) & (reference) \\
\hline Core COE Site ${ }^{\mathrm{b}}$ & & 0.95 & 1.05 \\
\hline Gender of physician (female) & & 0.92 & 0.75 \\
\hline \multicolumn{4}{|l|}{ Step 3: Satisfaction factors } \\
\hline Visit content & & & $11.53^{* * *}$ \\
\hline Access & & & $2.93^{* * *}$ \\
\hline Amenities & & & $2.13^{* *}$ \\
\hline Pseudo $R^{2}$ & 0.064 & 0.074 & $0.469^{+}$ \\
\hline
\end{tabular}

aThe dependent variable is dichotomous: overall visit rated as "excellent" compared with other ratings.

${ }^{\mathrm{b}} \mathrm{COE}$, National Center of Excellence in Women's Health.

${ }^{* * *} p<0.001 ; * * p<0.01 ; * p<0.05$.

${ }^{\dagger}$ By the Chi-square test, the stepwise increment in the Pseudo $R^{2}$ is significant at $p<0.001$.

all visit satisfaction in step three and add significantly to variance explained by the model (as indicated by increment to pseudo $R^{2}$ ). Among the factor scores, visit content is the strongest predictor and amenities is the weakest predictor for both women and men. In step three, perceived health status and Medicaid enrollment persist as significant predictors among women, and reason for visit remains significant among men.

Visit content is the strongest predictor of overall visit satisfaction for both women and men, and this factor deals most directly with the clinical interaction between patients and providers. Although gender differences were not observed in the items comprising the visit content factor in the unadjusted analysis shown in Table 2, a regression model was constructed to further ex- plore whether these items reveal gender differences in an adjusted analysis. This model controls for the same covariates as in Tables 3 and 4 , but it replaces the visit content factor score with the individual items making up that factor.

Table 5 shows that, after adjusting for all covariates, the odds of reporting that the overall visit was "excellent" are significantly increased with higher levels of satisfaction with the amount of time spent with the doctor for both women and men. Aside from this item in common, women and men appear to find different aspects of visit content to be important to their overall satisfaction. For women, satisfaction with the doctor's ability to answer questions clearly, with how well the doctor knew what happened at other visits, and with nursing care are significant predictors 
Table 5. Visit Content Predictors of Overall Visit Satisfaction by Gender ${ }^{a}$ (Adjusted Relative Odds Ratios and 95\% Confidence Intervals)

\begin{tabular}{lcc}
\hline & $\begin{array}{c}\text { Women } \\
\text { Model fit }\end{array}$ & $\begin{array}{c}\text { Men } \\
\left(\text { Pseudo } \mathrm{R}^{2}=.47\right)\end{array}$ \\
\hline Personal interest shown in you and your medical problems & $1.35(0.81,2.25)$ & $3.65(1.45,9.22)^{*}$ \\
Doctor's ability to answer questions in a way you could understand & $2.47(1.32,4.61)^{*}$ & $1.07(0.43,2.65)$ \\
Thoroughness of examination/treatment & $0.93(0.55,1.57)$ & $0.99(0.46,2.16)$ \\
How well doctor knew what happened to you at other visits & $1.48(1.04,2.10)^{*}$ & $0.73(0.42,1.26)$ \\
Explanations of medical procedures and tests & $1.06(0.65,1.70)$ & $1.61(0.80,3.25)$ \\
Amount of time you spent with doctor & $1.73(1.13,2.63)^{*}$ & $2.02(1.08,3.79)^{*}$ \\
Overall satisfaction with nursing care & $1.77(1.21,2.59)^{*}$ & $1.05(0.56,1.97)$ \\
\hline
\end{tabular}

aThe dependent variable is dichotomous: overall visit rated as "excellent" compared with other ratings. Multiple logistic regression analyses control for all patient, visit, and satisfaction variables, except that individual items are substituted for the visit content factor score.

*Significant at $p<0.05$.

of overall visit satisfaction. These items might be construed as reflecting, respectively, the technical content of communication, continuity of care, and the multidisciplinary nature (i.e., the importance of nonphysician providers) of the care process. For men, satisfaction with the personal interest shown in them and their medical problems significantly predicts overall satisfaction. This item might be construed as reflecting the affective content of communication. Neither thoroughness of the examination nor explanations of medical procedures or tests were significant predictors for either women or men.

\section{DISCUSSION}

As expected based on other studies using generic outpatient satisfaction surveys, this analysis revealed few statistically significant differences between women and men in their ratings of various aspects of primary care visits in bivariate analyses. However, in multivariate analyses adjusting for patient and visit characteristics, some gender differences emerge. Although visit content (as opposed to access and amenities) is where both women and men place the most weight in assessing their overall primary care experiences, different aspects of the content of primary care visits are important to women and men. Most notably, women appear to be more concerned than men about the informational content of visits, continuity of care across visits, and the multidisciplinary aspects of care. Men, on the other hand, appear to be more concerned than women about the personal interest shown in them by their physicians.
These findings have both substantive and methodological implications. First, they suggest how to target quality improvement efforts differently for women and men. Addressing women's needs for health information and the consequences of fragmentation in their primary care appears to be key to increasing women's satisfaction with their healthcare visits. For men, enhancing the interpersonal aspects of the care process with physicians may be most critical.

Second, the findings suggest that there is room for improvement in the measurement of patient satisfaction. Generic outpatient satisfaction surveys, of which the one analyzed here is typical, may not be particularly useful for evaluating differences in women's primary care across different settings or programs. In the multivariate analyses, being seen in a core COE site did not affect overall satisfaction with the visit. Furthermore, the visit content factor score, which is the strongest predictor of overall visit satisfaction, did not differ significantly between core COE sites and other sites (data not shown). This means either that there are no differences in women's satisfaction with visit content across settings or that the instruments are not sensitive to differences in women's healthcare across settings. Because of the presumed differences in the content of care between COE and other sites, the latter explanation seems more likely.

Focus groups conducted by the investigators with over 50 women, recruited from the community and stratified by age (18-34, 35-55, 56 years and over), provide evidence that some aspects of primary care that women value are not tapped in standard patient satisfaction surveys. Women in all age groups reported that they valued providers 
who are familiar with their medical histories and prior visits; who initiate discussions of sensitive topics (e.g., sexual problems, domestic violence); who signal their openness to discussions of treatment options, including complementary or alternative medicine; and who respect women's opinions and ability to make decisions about their care. In addition, women preferred comprehensive services (including reproductive and nonreproductive care) at one visit, colocation of services (such as on-site mammography), and prompt and full reports of the results of tests and procedures. Such topics could be included in patient surveys to improve their sensitivity to women's concerns.

Analyzing patient satisfaction surveys for gender differences and developing more gender-sensitive measurement tools are important steps to improve the quality of women's heathcare. Evaluating quality in alternative organizational models for women's healthcare, such as COEs compared with traditional practices, requires measures that are sensitive to variations in the specific dimensions of women's primary care. Tuning in to women's concerns about their healthcare will enable us both to develop more sensitive measurement tools and to identify the healthcare delivery models that optimize patient satisfaction for women.

\section{REFERENCES}

1. Gold M, Wooldridge J. Surveying consumer satisfaction to assess managed-care quality: Current practices. Health Care Financing Rev 1995;16:155.

2. National Committee for Quality Assurance. HEDIS 2000 Narrative: What's in it and why it matters. Washington, DC: National Committee for Quality Assurance, 1999.

3. Rubin HR, Gandek B, Rogers WH, et al. Patients' ratings of outpatient visits in different practice settings: Results from the Medical Outcomes Study. JAMA 1993;270:835.

4. Scholle SH, Weisman CS, Anderson R, et al. Women's satisfaction with primary care: A new measurement effort from the PHS National Centers of Excellence in Women's Health. Women's Health Issues 2000;10:1.

5. Weiss GL. Patient satisfaction with primary medical care. Med Care 1988;26:383.

6. Kaplan SH. Satisfaction surveys: Does the information make a difference? Clin Perform Qual Healthcare 1996;4:216

7. Hall JA, Dornan MC. Patient sociodemographic char- acteristics as predictors of satisfaction with medical care: A meta-analysis. Soc Sci Med 1990;30:811.

8. Clancy CM, Massion CT. American women's health care: A patchwork quilt with gaps. JAMA 1992;268: 1918.

9. Kolodinsky J. Gender differences in satisfaction with primary care physicians in a managed care health plan. Women Health 1997;26:67.

10. Hall JA, Roter DL. Medical communication and gender: A summary of research. J Gender-Specific Med 1998;1:39.

11. Roter D, Hall JA. Why physician gender matters in shaping the physician-patient relationship. J Women's Health 1998;7:1093.

12. Collins KS, Schoen C, Joseph S, et al. Health concerns across a woman's lifespan: 1998 Survey of Women's Health. New York: The Commonwealth Fund, 1999.

13. Cleary PD, McNeil BJ. Patient satisfaction as an indicator of quality care. Inquiry 1988;25:25.

14. Cleary PD, Edgman-Levitan S. Health care quality: Incorporating consumer perspectives. JAMA 1997;278: 1608.

15. Davies AR, Ware JE. GHAA's consumer satisfaction survey and user's manual, 2nd ed. Washington, DC: Group Health Association of America, 1991.

16. Ware JE, Hays RD. Methods for measuring patient satisfaction with specific medical encounters. Med Care 1988;26:393.

17. Bertakis KD, Helms LJ, Callahan EJ, et al. The influence of gender on physician practice style. Med Care 1995;33:407.

18. Lurie N, Margolis KL, McGovern PG, et al. Why do patients of female physicians have higher rates of breast and cervical cancer screening? I Gen Intern Med 1997;12:34.

19. Office on Women's Health, U.S. Department of Health and Human Services. National Centers of Excellence in Women's Health Report Card. Washington, DC: U.S. Department of Health and Human and Services, 1999.

20. Leader S, Perales PJ. Provision of primary-preventive health care services by obstetrician-gynecologists. $\mathrm{Ob}-$ stet Gynecol 1995;85:391.

21. Weisman CS. Women's use of health care. Falik MM, Collins KS, eds. Women's health: The Commonwealth Fund survey. Baltimore, MD: Johns Hopkins University Press, 1996:19.

22. Bartman BA, Weiss KB. Women's primary care in the United States: A study of practice variation among physician specialties. J Women's Health 1993;2:261.

Address reprint requests to: Carol S. Weisman, Ph.D. Professor Department of Health Management and Policy University of Michigan School of Public Health 109 S. Observatory, Room M3138 Ann Arbor, MI 48109-2029 


\section{This article has been cited by:}

1. David L. Wood, Quimby E. McCaskill, Nancy Winterbauer, Edessa Jobli, Tao Hou, Peter S. Wludyka, Kristi Stowers, William Livingood. 2008. A Multi-Method Assessment of Satisfaction with Services in the Medical Home by Parents of Children and Youth with Special Health Care Needs (CYSHCN). Maternal and Child Health Journal . [CrossRef]

2. M. Geraedts, R. Amhof. 2008. Geschlechterunterschiede beim Bedarf an Qualitätsinformationen über Einrichtungen der Gesundheitsversorgung. Bundesgesundheitsblatt - Gesundheitsforschung - Gesundheitsschutz 51:1, 53-60. [CrossRef]

3. Lauri Kuosmanen, Heli Hatonen, Anna Riitta Jyrkinen, Jouko Katajisto, Maritta Valimaki. 2006. Patient satisfaction with psychiatric inpatient care. Journal of Advanced Nursing 55:6, 655-663. [CrossRef]

4. Steven M. Wright, Thomas Craig, Stacey Campbell, Jim Schaefer, Charles Humble. 2006. Patient Satisfaction of Female and Male Users of Veterans Health Administration Services. Journal of General Internal Medicine 21:S3, S26-S32. [CrossRef]

5. Steven M. Wright, Thomas Craig, Stacey Campbell, Jim Schaefer, Charles Humble. 2006. Patient satisfaction of female and male users of veterans health administration services. Journal of General Internal Medicine 21:3, S26. [CrossRef]

6. Sheila A. Turris. 2005. Unpacking the concept of patient satisfaction: a feminist analysis. Journal of Advanced Nursing 50:3, 293-298. [CrossRef]

7. Ivy M. Alexander. 2004. Characteristics of and Problems With Primary Care Interactions Experienced by an Ethnically Diverse Group of Woman. Journal of the American Academy of Nurse Practitioners 16:7, 300-310. [CrossRef]

8. Mark S. Walker, Stephen L. Ristvedt, Bruce H. Haughey. 2003. Patient care in multidisciplinary cancer clinics: Does attention to psychosocial needs predict patient satisfaction?. Psycho-Oncology 12:3, 291-300. [CrossRef]

9. Bevanne A. Bean-Mayberry, Chung-Chou H. Chang, Melissa A. Mc Neil, Jeff Whittle, Patricia M. Hayes, Sarah Hudson Scholle. 2003. Patient Satisfaction in Women's Clinics Versus Traditional Primary Care Clinics in the Veterans Administration. Journal of General Internal Medicine 18:3, 175. [CrossRef]

10. Ingrid Eijk, Herman Sixma, Tamara Smeets, Fernando Tavarela Veloso, Selwyn Odes, Sean Montague, Giovanni Fornaciari, Bjorn Moum, Reinhold StockbruggerStockbrugger, Maurice Russel. 2002. Quality of health care in inflammatory bowel disease: development of a reliable questionnaire (QUOTE-IBD) and first results. The American Journal of Gastroenterology 96:12, 3329-3336. [CrossRef] 